\title{
Access-Related Infections Involving the Buttonhole Technique
}

\author{
Shigeki Toma ${ }^{a}$ Takahiro Shinzato $^{b}$ Kunihiro Hayakawa ${ }^{c}$ \\ ${ }^{a}$ Toma Clinic, Okinawa, ${ }^{b}$ Daiko Medical Engineering Research Institute, Nagoya, and ${ }^{\mathrm{c} A i c h i}$ Clinic, Toyohashi, Japan
}

\section{Key Words}

Buttonhole cannulation · Infection · Blood access .

Staphylococcus aureus $\cdot$ Hemodialysis

\begin{abstract}
Purpose: In this study, we discuss a mechanism of development of access-related Staphylococcus aureus infections in patients on buttonhole $(\mathrm{BH})$ method and logically construct a measure to prevent such infections on the basis of the mechanism. Summary: S. aureus can colonize a BH track. Once $S$. aureus colonizes a BH track, access-related infections may develop when the equilibrium is upset between the factors of host resistance and a level of bacterial growth in a $\mathrm{BH}$ track. Thus, the logically constructed measure to prevent access-related infections are as follows: (1) decolonization of $S$. aureus from a $\mathrm{BH}$ track by applying mupirocin ointment to a $\mathrm{BH}$ entry site when a patient has been proven to be a carrier of $S$. aureus in the track, (2) prevention of bacterial invasion of the $\mathrm{BH}$ track by a new method to remove a scab completely, and (3) control of bacterial growth in the $\mathrm{BH}$ track by disinfecting the site with diluted povidone-iodine solution $(0.1 \%$ povidone-iodine solution) before access vessel cannulation.
\end{abstract}

(C) 2016 S. Karger AG, Basel

\section{Introduction}

Several studies have reported more frequent occurrences of access-related infections in the buttonhole $(\mathrm{BH})$ method [1-9]. The consequences of such complications are often serious when Staphylococcus aureus is a causative bacteria $[1-4,6,7,9]$. This provokes the hesitation to use $\mathrm{BH}$ cannulation in routine clinical practice $[8,9]$. Therefore, whether the $\mathrm{BH}$ method will further prevail or no longer be utilized may depend on the results of a search for a measure to prevent access-related infections.

Thus, in this review article, we first discuss a mechanism of development of access-related $S$. aureus infection in patients on the $\mathrm{BH}$ method, based on literature reporting epidemiological studies of $S$. aureus infections in hemodialysis (HD) patients. Second, on the basis of the mechanism of development of such infections, we logically construct a measure to prevent access-related $S$. aureus infections associated with the $\mathrm{BH}$ technique.

\section{Mechanism of Development of Access-Related Infections by S. aureus}

Autoinoculation Routes of S. aureus in HD Patients

$S$. aureus colonizing permanently or temporarily in the anterior nares [10-15] may be autoinoculated on the skin overlying the vascular access site via a patient's own hand $[13,15]$. Eventually, such $S$. aureus colonizing the skin enters the patient's bloodstream so that access-related infections develop [13, 14]. In this autoinoculation route of $S$. aureus, the route from the anterior nares to the skin is thought to be common to all HD patients, irrespective of the type of a vascular access cannulation method. However, HD patients on the $\mathrm{BH}$ method have a unique route between the skin and the access vessel;

\section{KARGER}

E-Mail karger@karger.com www.karger.com/bpu (c) 2016 S. Karger AG, Basel

0253-5068/16/0414-0306\$39.50/0
Takahiro Shinzato, $\mathrm{MD}, \mathrm{PhD}$

Daiko Medical Engineering Research Institute

4-16-23 Daiko, Higashi-ku

Nagoya, Aichi-ken 461-0043 (Japan)

E-Mail shinzato@xj8.so-net.ne.jp 
that is, the $\mathrm{BH}$ track. The $\mathrm{BH}$ track can play a key role in the development of access-related infections in these patients.

\section{BH Track Colonization with S. aureus}

Nesrallah et al. [4] have reported that access-related infections by $S$. aureus were prevented by applying mupirocin ointment to a $\mathrm{BH}$ entry site. Their report suggests that $S$. aureus could colonize a $\mathrm{BH}$ track.

One notable point in the report of Nesrallah et al. [4] is the timing of the application of mupirocin ointment. They applied the ointment after an HD session. This timing of ointment application may indicate that the effectiveness of mupirocin ointment was not obtained through the prevention of $S$. aureus from entering an access vessel associated with dull needle insertion. Nor may this indicate effectiveness through the prevention of $S$. aureus from invading a $\mathrm{BH}$ track during $\mathrm{HD}$. The report of Nesrallah et al. [4] may rather indicate that the application of mupirocin ointment to a $\mathrm{BH}$ entry site decolonized a $\mathrm{BH}$ track, which harbored $S$. aureus.

In order to verify whether $S$. aureus can colonize a $\mathrm{BH}$ track, we attempted to isolate bacteria from $\mathrm{BH}$ tracks in 59 patients who had no manifestations of access-related infections. The $\mathrm{BH}$ entry site was disinfected with $0.1 \%$ povidone-iodine solution before and after the patients' scabs were removed by the conventional method. Thereafter, a sterile toothpick was inserted into the $\mathrm{BH}$ tracks to a depth of between 2 and $3 \mathrm{~mm}$ and then removed. Cultures were obtained from the removed toothpicks. As a result, S. aureus was isolated in $3(5.1 \%)$ of the 59 patients and S. epidermidis in $8(13.6 \%)$ of the same patients (unpublished data). These results indicate that $S$. aureus can colonize a $\mathrm{BH}$ track.

\section{Development of Access-Related Infections in Patients}

Carrying S. aureus in a BH Track

Infection is known to develop when the equilibrium is upset between the factors of host resistance and the actions of bacteria, either as a result of impairment of the host defense mechanisms or by an increase in the bacterial inoculum [16]. It has been reported that in a host with intact defense mechanisms, a level of bacterial growth of greater than 100,000 organisms per gram of tissue is necessary to cause wound infection and the potential for invasive sepsis for most species of bacteria [16]. Access-related infections by S. aureus may also develop when bacterial growth exceeds a certain level in the $\mathrm{BH}$ tracks in patients who are carrying $S$. aureus within their tracks.

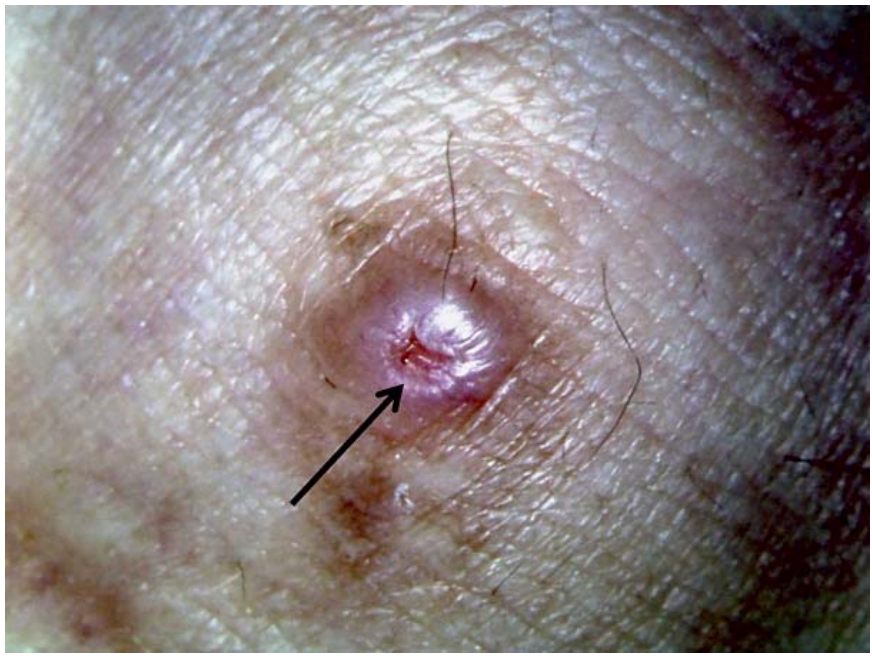

Fig. 1. A BH entry site deformed by bulging. The opening of this $\mathrm{BH}$ track expands, as indicated by the arrow.

\section{Factor for Bacteria to Enter a BH Track}

Careful observation of a BH entry site after removal of a scab often reveals bulging of the site. In addition, an expanded opening of a $\mathrm{BH}$ track is sometimes observed at the summit of the bulging (fig. 1). Sato et al. [17] have reported their study results suggesting that this bulging deformity of a $\mathrm{BH}$ entry site would be a factor of bacterial colonization in a $\mathrm{BH}$ track.

Sato et al. [17] used a multivariate logistic regression analysis to examine associations between various factors including this bulging deformity of a $\mathrm{BH}$ entry site and access-related infections occurring over the past 18 months for $320 \mathrm{BH}$ entry sites of 166 patients.

Their results showed access-related infections to be significantly associated with only the bulging deformity of a $\mathrm{BH}$ entry site. According to their analysis, the risk of access-related infections was 5,369 times greater in the entry site with bulging deformity than in the flat entry site (table 1). These results suggest that at least one major factor of bacterial colonization in a $\mathrm{BH}$ track is bulging deformity of a $\mathrm{BH}$ entry site.

\section{Mechanism of Increase in Incidence of Access-Related}

Infection Associated with Bulging Deformity of $B H$

Entry Sites

One reason for increase in the risk of access-related infections associated with bulging deformity of a $\mathrm{BH}$ entry site may be difficulty of scab removal at a deformed entry site. As indicated in fig. 2, despite efforts to remove a scab completely, scab fragments often remain at a $\mathrm{BH}$ entry site especially when the same site exhibits a bulging deformity. 
Fig. 2. A BH entry site before and after scab removal procedure. There are fragments of a scab at the $\mathrm{BH}$ entry site, even after the intended removal.

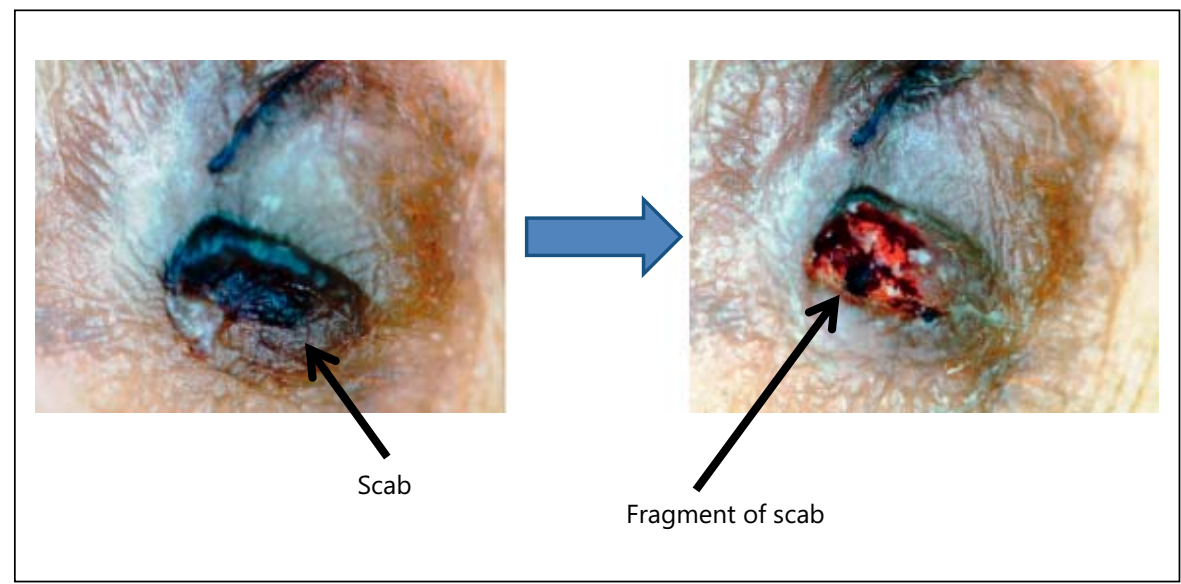

Table 1. Multivariate-adjusted OR and 95\% CI for access-related infection

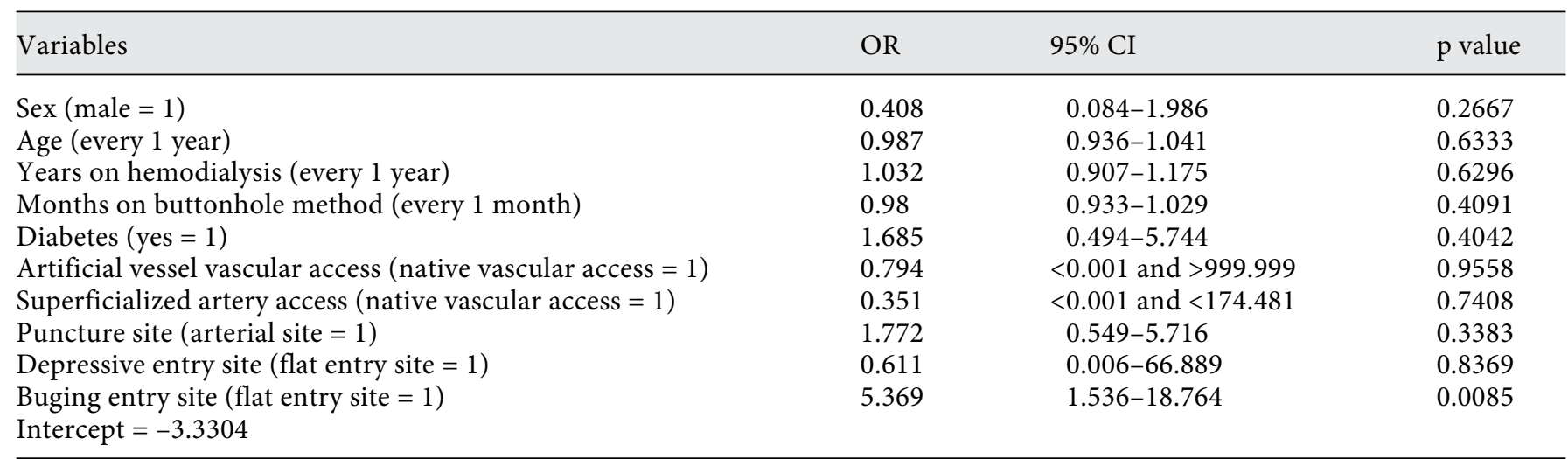

Adapted from Sato et al. [17].

It has been reported that bacteria colonizing the skin can enter a scab formed on the wound surface [18]. Similarly, a scab created at a BH entry site could be contaminated with bacteria colonizing the skin. If the remaining fragments of the scab contaminated with bacteria are pushed into a $\mathrm{BH}$ track associated with dull needle insertion, bacteria could colonize a $\mathrm{BH}$ track. Once bacteria colonize a $\mathrm{BH}$ track, access-related infections would develop when the equilibrium is upset between the factors of host resistance and the level of bacterial growth in a $\mathrm{BH}$ track.

The other plausible reason for an increase in the risk of access-related infections may be expansion of the opening of a $\mathrm{BH}$ track. When a $\mathrm{BH}$ entry site gets deformed by bulging, the opening of the $\mathrm{BH}$ track often expands at the site. The degree of expansion of the opening is thought to be large enough to allow bacteria to invade the $\mathrm{BH}$ track, but too small to allow disinfectants to enter the same track. Thus, such expansion of the opening of a $\mathrm{BH}$ track can also cause access-related infections through an easy invasion of the track by bacteria.

\section{Mechanism of Bulging Deformity Formation at $B H$ Entry Sites and Expansion of the Opening of a $\mathrm{BH}$ Track}

A dull needle grazes the surface of a $\mathrm{BH}$ track at every cannulation. This may result in granulation of the tissue surrounding the $\mathrm{BH}$ track. Over a long period of time, the amount of the granulation tissue will increase. Such excessive granulation tissue (hypertrophic granulation) will push the skin up at that $\mathrm{BH}$ entry site, resulting in a bulging deformity.

This hypothesis of bulging deformity formation is supported by the microscopic features of a $\mathrm{BH}$ entry site in a 
specimen taken from a patient who died after receiving BH cannulation for 3 years. In the specimen (fig. 3), a large amount of granulation tissue is observed surrounding the BH track [17].

Expansion of an opening of a $\mathrm{BH}$ track is seen only when a BH entry site is deformed by bulging. Accordingly, the expansion of the opening may be due to hypertrophic granulation around a $\mathrm{BH}$ track.

If this hypothesis is correct, either bulging deformity of a $\mathrm{BH}$ entry site or expansion of an opening of a $\mathrm{BH}$ track is unpreventable. Procedures to prevent access-related infections must be considered based on the premise that a $\mathrm{BH}$ entry site will be deformed by bulging and a $\mathrm{BH}$ track opening will expand over long-term $\mathrm{BH}$ cannulation.

\section{Logically Constructed Measure to Prevent Access-Related Infections}

The procedures for preventing access-related infections by $S$. aureus involve 3 steps: (1) performance to decolonize a $\mathrm{BH}$ track with $S$. aureus, (2) performance to prevent $S$. aureus colonization or re-colonization in a $\mathrm{BH}$ track, and (3) control of $S$. aureus growth in a BH track.

\section{Eradication of S. aureus in Carrier Patients}

Anterior Nares. Tacconelli et al. [19] performed a meta-analysis and indicated that nasal application of mupirocin ointment reduced the rate of $S$. aureus infections by $80 \%$ among HD patients. Nevertheless, nasal application of mupirocin ointment is still controversial. Mupirocin ointment is effective at removing $S$. aureus from the anterior nares, but nasal relapses are common within 6 months [15]. Moreover, it has been reported that mupirocin resistance to $S$. aureus often emerges associated with prophylactic use of mupirocin ointment [20-23].

BH Track. Nesrallah et al. [4] have reported that accessrelated infections by $S$. aureus were prevented by applying mupirocin ointment to a $\mathrm{BH}$ entry site. Their report may indicate that $S$. aureus can be eradicated from $\mathrm{BH}$ tracks by applying mupirocin ointment to a $\mathrm{BH}$ entry site.

Nesrallah et al. [4] applied mupirocin ointment to a $\mathrm{BH}$ entry site indefinitely. However, once $S$. aureus is successfully eradicated from a $\mathrm{BH}$ track, the application of mupirocin ointment may need to be discontinued because extended use of mupirocin ointment can cause the emergence of mupirocin-resistant $S$. aureus [20-23].

Currently, there have been no studies on the period of a prophylactic application of mupirocin ointment to a $\mathrm{BH}$

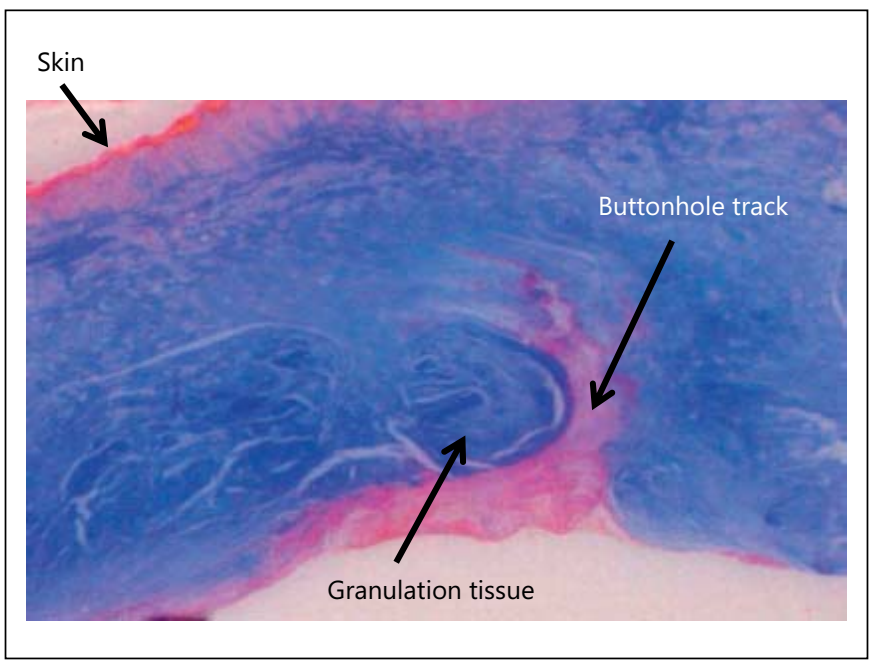

Fig. 3. Microscopic features of BH entry site tissue, stained by the Mallory-Azan method. Granulation was observed beneath the skin and in the 3-5 $\mathrm{mm}$ range from the $\mathrm{BH}$ track. There was also skin proliferation in the granulation area (adapted from Sato et al. [17]).

entry site. For reference, we are applying $2 \%$ mupirocin ointment for 2 weeks to a BH entry site at every HD session after hemostasis achievement when a patient was proven to be a carrier of $S$. aureus in a BH track.

\section{Prevention of Bacterial Invasion of the BH Track}

In order to prevent colonization or re-colonization of the BH track with S. aureus, scab fragments contaminated with $S$. aureus must not be allowed to be pushed into a $\mathrm{BH}$ track by a dull needle when the needle is inserted into the track. The below new method to remove a scab completely [24] will effectively prevent such an event.

The new method to remove a scab completely consists of 2 steps. The first step of the method is the moist healing procedure of a $\mathrm{BH}$ entry site, which is performed immediately after hemostasis achievement. In this step, sterile dressings are applied to BH entry sites. The second step of the method involves removal of a scab by rubbing the $\mathrm{BH}$ entry sites with a towel during bathing, which is performed on the night before the next HD.

In the first step, before a sterile dressing is applied to a $\mathrm{BH}$ entry site, the site is disinfected with $0.1 \%$ povidoneiodine solution. For the reasons that the diluted povidone-iodine solution, which is less toxic, is used as a disinfectant and that the entry site is treated with the moist healing approach, stratum corneum is formed beneath the scab by the second step.

In the second step, the scab formed at the entry site is removed. Patients are instructed to remove the dressings 
$24 \mathrm{~h}$ after the dressings are applied and to wipe off the created scabs using a towel during bathing on the night before the next HD. The reason for easy scab removal in this method is that stratum corneum is already formed beneath the scab and the scab is softened by absorbing water during bathing.

When patients visit their dialysis facility for the next $\mathrm{HD}$, there is no risk of pushing scab fragments into the $\mathrm{BH}$ track by a dull needle because no scabs exist at the entry sites. The entry sites are covered with a thin transparent membrane and the opening of the $\mathrm{BH}$ tracks appear red through the membrane (fig. 4).

\section{Control of Bacterial Growth in a BH Track}

When a $\mathrm{BH}$ track has been used over an extended period, the opening of the track expands so that a barrier disappears for bacteria between the skin and the $\mathrm{BH}$ track. This might allow bacteria to enter the portion directly below the opening of the $\mathrm{BH}$ track from the adjoining skin. Therefore, in order to curb colonization of a $\mathrm{BH}$ track with $S$. aureus, a necessary procedure may be to disinfect this portion of a $\mathrm{BH}$ track at every $\mathrm{HD}$ session before an access vessel is cannulated with a dull needle.

Before access vessel cannulation, a BH entry site covered by the stratum corneum is first disinfected with $0.1 \%$ povidone-iodine solution. Next, a piece of unwoven fabric $(10 \times 10 \mathrm{~mm})$ soaked in $0.1 \%$ povidone-iodine solution is placed on the disinfected BH entry site. Thereafter, a portion of the unwoven fabric soaked in disinfectant is pushed approximately $2-3 \mathrm{~mm}$ into a $\mathrm{BH}$ track with a dull needle by piercing the stratum corneum that covers the BH entry site (fig. 5). The unwoven fabric is kept in place for $1 \mathrm{~min}$ before that fabric is removed. Once these processes are completed, the access vessel is punctured with the dull needle through the $\mathrm{BH}$ track.

For disinfection of the $\mathrm{BH}$ entry site and the portion directly below the opening of the $\mathrm{BH}$ track, $0.1 \%$ povidoneiodine solution was used as a disinfectant, instead of commercially available $10 \%$ povidone-iodine solution because this diluted povidone-iodine solution has paradoxically greater bactericidal activity than $10 \%$ povidone-iodine solution [25]. The American Center for Disease Control and Prevention has recently announced greater bactericidal activity of $0.1 \%$ povidone-iodine solution [26].

In terms of cytotoxicity, $0.1 \%$ povidone-iodine solution may be viable for disinfecting $\mathrm{BH}$ entry sites. Whitacre et al. [27] have reported that concentration of $0.5 \%$ povidone-iodine solution exhibited no detectable adverse changes in the eyes of 9 of 10 studied rabbits. In contrast, Balin et al. [28] have reported that even a low concentra-

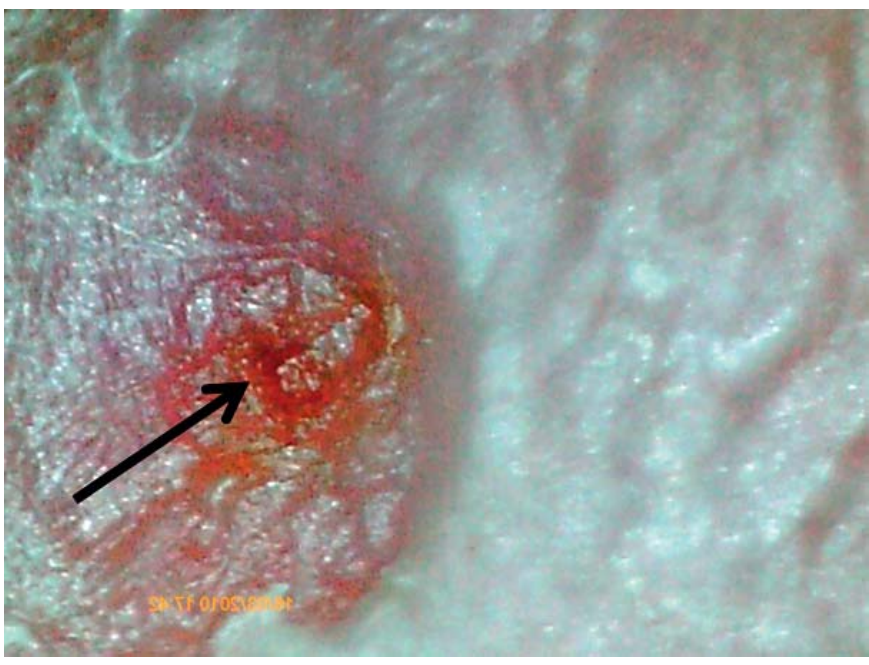

Fig. 4. Enlarged photograph of the BH entry site of a patient treated with the new procedure. The photograph, magnified $25 \times$, was taken before the next HD. The opening of the BH track appeared red through the membrane (indicated by the arrow; adapted from Shinzato et al. [24]).

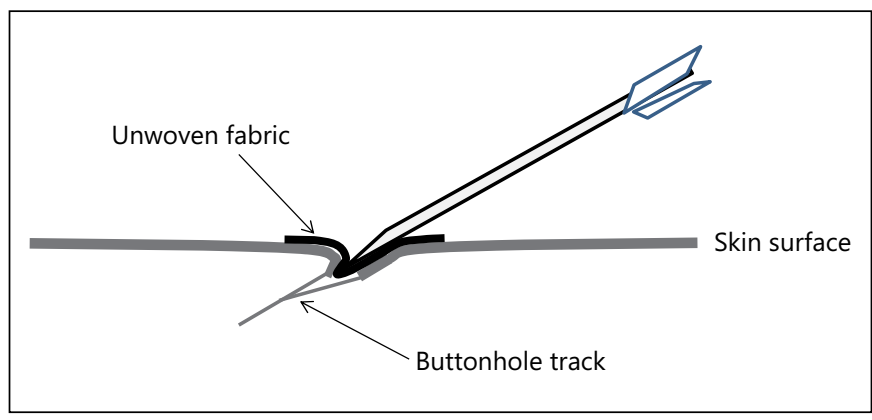

Fig. 5. Disinfection of a $\mathrm{BH}$ track portion directly below the opening. The central portion of the unwoven fabric, soaked in disinfectant, is pushed into the $\mathrm{BH}$ track approximately $2-3 \mathrm{~mm}$ with a dull needle by piercing the stratum corneum that covers the $\mathrm{BH}$ entry site.

tion of povidone-iodine solution at $0.1 \%$ does have toxicity. In our research, such diluted povidone-iodine solution did not interfere with the stratum corneum formation beneath a scab [24].

In order to examine the effectiveness of the abovementioned method to disinfect the portion directly below the opening of the $\mathrm{BH}$ track, we took cultures from the $\mathrm{BH}$ track prior to the disinfection and again $10 \mathrm{~min}$ after the disinfection. These cultures were taken from the patients who had carried either S. aureus or S. epidermidis 2 months prior in the $\mathrm{BH}$ track. Of the 3 patients who had carried S. aureus, 2 patients still had S. aureus in the track. 
In these 2 patients, $\mathrm{BH}$ track cultures turned negative for S. aureus after the disinfection. On the other hand, of the 8 patients who had carried S. epidermidis 2 months prior in the BH track, 5 patients still had S. epidermidis. In 3 of these 5 patients, $\mathrm{BH}$ track cultures turned negative for $S$. epidermidis after the disinfection (unpublished data).

These results indicate that disinfection of a $\mathrm{BH}$ track does not always eradicate bacteria from within a $\mathrm{BH}$ track. Nevertheless, disinfection of a $\mathrm{BH}$ track may still be meaningful because the purpose of this disinfection is not to eradicate bacteria from a $\mathrm{BH}$ track, but rather to control bacterial growth in a track.

\section{Clinical Effectiveness of Logically Constructed Measure for Prevention of Access-Related Infections}

Each of the above-mentioned procedures to prevent access-related infections appears to be safe and effective to intercept bacteria at the respective autoinoculation point. Therefore, the next step may be implementa- tion of all procedures together in routine clinical practice in order to verify collective effectiveness of the procedures.

\section{Conclusion}

Some patients carry $S$. aureus in their BH tracks. In these patients, the track must be decolonized with $S$. aureus by applying mupirocin ointment to a $\mathrm{BH}$ entry site. At every $\mathrm{HD}$, bacterial invasion of the $\mathrm{BH}$ track must be prevented by a new method to remove a scab completely, and bacterial growth in the $\mathrm{BH}$ track must be controlled by disinfecting the site with $0.1 \%$ povidone-iodine solution before access vessel cannulation.

\section{Disclosure Statement}

Dr. Takahiro Shinzato receives a consultant fee from the Asahikasei Medical Corporation where he is an advisor.

\section{References}

1 Doss S, Schiller B, Moran J: Buttonhole cannulation - an unexpected outcome. Nephrol Nurs J 2008;35:417-419.

2 Gray N: The risk of sepsis from buttonhole needling must be appreciated. Nephrol Dial Transplant 2010;25:2385-2386.

3 Birchenough E, Moore C, Stevens K, Stewart $S$ : Buttonhole cannulation in adult patients on hemodialysis: an increased risk of infection? Nephrol Nurs J 2010;37:491-498.

4 Nesrallah GE, Cuerden M, Wong JH, Pierratos A: Staphylococcus aureus bacteremia and buttonhole cannulation: long-term safety and efficacy of mupirocin prophylaxis. Clin J Am Soc Nephrol 2010;5:1047-1053.

5 Chow J, Rayment G, San Miguel S, Gilbert M: A randomised controlled trial of buttonhole cannulation for the prevention of fistula access complications. J Ren Care 2011;37:85-93.

6 Labriola L, Crott R, Desmet C, André G, Jadoul $\mathrm{M}$ : Infectious complications following conversion to buttonhole cannulation of native arteriovenous fistulas: a quality improvement report. Am J Kidney Dis 2011;57:442-448.

7 MacRae JM, Ahmed SB, Atkar R, Hemmelgarn BR: A randomized trial comparing buttonhole with rope ladder needling in conventional hemodialysis patients. Clin J Am Soc Nephrol 2012;7:1632-1638.

8 Muir CA, Kotwal SS, Hawley CM, Polkinghorne K, Gallagher MP, Snelling P, Jardine MJ: Buttonhole cannulation and clinical outcomes in a home hemodialysis cohort and systematic review. Clin J Am Soc Nephrol 2014;9:110-119.

9 Lok CE, Sontrop JM, Faratro R, Chan CT, Zimmerman DL: Frequent hemodialysis fistula infectious complications. Nephron Extra 2014;4:159-167.

10 Kirmani N, Tuazon CU, Murray HW, Parrish AE, Sheagren JN: Staphylococcus aureus carriage rate of patients receiving long-term hemodialysis. Arch Intern Med 1978; 138:16571659.

11 Yu VL, Goetz A, Wagener M, Smith PB, Rihs JD, Hanchett J, Zuravleff JJ: Staphylococcus aureus nasal carriage and infection in patients on hemodialysis. Efficacy of antibiotic prophylaxis. N Engl J Med 1986;315:91-96.

12 Kaplowitz LG, Comstock JA, Landwehr DM, Dalton HP, Mayhall CG: Prospective study of microbial colonization of the nose and skin and infection of the vascular access site in hemodialysis patients. J Clin Microbiol 1988;26: 1257-1262.

13 Boelaert JR, Van Landuyt HW, Gordts BZ, De Baere YA, Messer SA, Herwaldt LA: Nasal and cutaneous carriage of Staphylococcus aureus in hemodialysis patients: the effect of nasal mupirocin. Infect Control Hosp Epidemiol 1996;17:809-811.

14 Ena J, Boelaert JR, Boyken LD, Van Landuyt HW, Godard CA, Herwaldt LA: Epidemiology of Staphylococcus aureus infections in patients on hemodialysis. Infect Control Hosp Epidemiol 1994;15:78-81.
15 Doebbeling BN, Breneman DL, Neu HC, Aly R, Yangco BG, Holley HP Jr, Marsh RJ, Pfaller MA, McGowan JE Jr, Scully BE, et al: Elimination of Staphylococcus aureus nasal carriage in health care workers: analysis of six clinical trials with calcium mupirocin ointment. The Mupirocin Collaborative Study Group. Clin Infect Dis 1993;17:466-474.

16 Robson MC: Wound infection. A failure of wound healing caused by an imbalance of bacteria. Surg Clin North Am 1997;77:637650.

17 Sato S, Shinzato T, Sakai N, Ohkuri K, Sasaki M, Nakai S, Toma S: Deformity of buttonhole entry site causes higher frequency of vascular access-related infection. Contrib Nephrol 2015; 186:48-56.

18 Zhao G, Hochwalt PC, Usui ML, Underwood RA, Singh PK, James GA, Stewart PS, Fleckman P, Olerud JE: Delayed wound healing in diabetic $(\mathrm{db} / \mathrm{db})$ mice with pseudomonas aeruginosa biofilm challenge: a model for the study of chronic wounds. Wound Repair Regen 2010;18:467-477.

19 Tacconelli E, Carmeli Y, Aizer A, Ferreira G, Foreman MG, D'Agata EM: Mupirocin prophylaxis to prevent Staphylococcus aureus infection in patients undergoing dialysis: a meta-analysis. Clin Infect Dis 2003;37:16291638.

20 Kavi J, Andrews JM, Wise R: Mupirocin-resistant Staphylococcus aureus. Lancet 1987;2: 1472-1473. 
21 Upton A, Lang S, Heffernan H: Mupirocin and staphylococcus aureus: a recent paradigm of emerging antibiotic resistance. J Antimicrob Chemother 2003;51:613-617.

22 Simor AE, Stuart TL, Louie L, Watt C, OfnerAgostini M, Gravel D, Mulvey M, Loeb M, McGeer A, Bryce E, Matlow A; Canadian nosocomial infection surveillance program: $\mathrm{Mu}-$ pirocin-resistant, methicillin-resistant Staphylococcus aureus strains in Canadian hospitals. Antimicrob Agents Chemother 2007;51: 3880-3886.
23 Hogue JS, Buttke P, Braun LE, Fairchok MP: Mupirocin resistance related to increasing mupirocin use in clinical isolates of methicillin-resistant Staphylococcus aureus in a pediatric population. J Clin Microbiol 2010;48: 2599-2600.

24 Shinzato T, Sasaki M, Ota N, Shibata K, Fukui $\mathrm{H}$, Toma S, Maeda K: A new method that enables complete removal of scabs at buttonhole entry sites. Contrib Nephrol 2015;186:41-47.

25 Berkelman RL, Holland BW, Anderson RL: Increased bactericidal activity of dilute preparations of povidone-iodine solutions. J Clin Microbiol 1982;15:635-639.
26 Rutala WA, Webe DJ: Healthcare Infection Control Practices Advisory Committee (HICPAC): Guideline for Disinfection and Sterilization in Healthcare Facilities, 2008

27 Whitacre MM, Crockett RS: Tolerance of intravitreal povidone-iodine in rabbit eyes. Curr Eye Res 1990;9:725-732.

28 Balin AK, Pratt L: Dilute povidone-iodine solutions inhibit human skin fibroblast growth. Dermatol Surg 2002;28:210-214. 